\title{
Mothers' Perception of Family and School Life When Their Children Have a Chronic Condition
}

\author{
Amanda F. Hopkins ${ }^{\mathrm{a}}$, Agatha M. Gallo
}

\begin{abstract}
Background: It has long been recognized that family and school are important influences on the growth and development of a child with a chronic condition. Despite this growing consensus, few investigators have looked at this relationship. Guided by the Family Management Style Framework (FMSF), the purpose of this qualitative study was to describe the perceptions of mothers of children with chronic conditions about family and school life.
\end{abstract}

Methods: This study was a secondary analysis of data gathered from 41 mothers who were interviewed for a larger study on families who have a child with a chronic condition. A constant comparative method was utilized for analyzing verbatim audio recorded interview transcripts.

Results: The three themes identified were: view of child, family illness management and school. Four parameters described the view of child: the child's current physical health, the child's adjustment to the condition, the child's participation in self-care activities, and the outlook on the child's future. For family illness management, mothers described a variety of specific strategies and behaviors used by the family to manage the child's condition in the context of the home. The school theme focused on communication between mothers and the school system, resources provided to the child's school, specific parental concerns regarding their children and school, and confidence in the school personnel.

Conclusions: Results described the mothers' perceptions of school life and showed that this is the first step in understanding how to as-

Manuscript accepted for publication October 3, 2012

${ }^{a}$ Amanda F. Hopkins, University of Illinois at Chicago, Urbana Regional Program, 408 South Goodwin Avenue,Urbana, Illinois 61801, USA

b Agatha M. Gallo, University of Illinois at Chicago, College of Nursing, Department of Women, Children and Family Health Science, 845 S. Damen Avenue, Chicago, IL 60612, USA

${ }^{\mathrm{c} C}$ Corresponding author: Amanda F. Hopkins, University of Illinois at Chicago, Urbana Regional Program, 408 South Goodwin Avenue,Urbana, Illinois 61801, USA. Email: hopkinsa@illinois.edu

doi: http://dx.doi.org/10.4021/ijcp54w sist these families in managing the care of the child with a chronic condition in the school setting.

Keywords: Pediatric chronic conditions; School health; Qualitative research; Mothers' perceptions; Secondary analysis

\section{Introduction}

As a result of major advances in science and technology, improvements in the medical treatments for children with chronic conditions are being made at an astonishing rate. Researchers estimate that $10-30 \%$ of all children in the United States have a chronic condition [1-3] and 58\% of students with chronic conditions routinely miss school days and $10 \%$ miss more than $25 \%$ of the academic school year [4]. Other studies indicate a positive association between family-school relationships and reduced school absences and student academic successes [5-7]. These relationships were found to be most effective when the goal was to address the ongoing needs [8], foster collaboration and two-way communication among families and schools, and includes characteristics such as trust, commitment, respect and shared vision $[9,10]$.

Family-centered care has become the gold standard of care for school age children with chronic conditions [11] and one of the major principles within this framework was a strong working relationship between the family and the school system.

The purpose of this study was to describe mothers' perspectives about school life within the context of their perception of their children with a chronic condition and the overall family management of the condition.

\section{Materials and Methods}

This analysis uses a qualitative descriptive design and a secondary analysis approach of data gathered from 41 mothers who were interviewed with the original purpose of identifying a range of information management patterns of families who have a child with a chronic single gene condition [12]. 
The following study was approved by the University of Illinois at Chicago Institutional Review Board as a secondary analysis study.

Data from 41 mothers who were the primary caregivers of their children with either sickle cell disease (SCD) or cystic fibrosis (CF) were analyzed. The sample was solely comprised of Caucasian $(\mathrm{n}=16 ; \mathrm{CF})$ and African-American $(\mathrm{n}=25$; SCD) mothers. Inclusion criteria were: a parent or family member described as primary caregiver involved in the everyday management of the child's care; parents spoke and understood English, and the target child with the chronic genetic condition was school-aged and within 2 years of their expected grade in school, was the oldest with the condition in the family if more than one child was affected, was biological for at least one parent, and attended a regular classroom setting. No limitations were placed on the sample in regard to demographics such as gender, race, ethnicity, socioeconomic status, and education.

To recruit families for the original study, arrangements were made with several facilities in a metropolitan area to assist in identifying and recruiting families that met the inclusion criteria. A letter describing the nature of the study was sent to parents from the clinic directors inviting them to participate in the study. Parents were also recruited either in person or by a member of the research team during a clinic visit. Those interested in participating in the study then contacted the original researchers to discuss the process further. Individual interviews took place in private, quiet settings, and were digitally recorded.

A semi-structured, in-depth interview guide developed from the literature was used in the original study to interview the mothers related to the three major components of the Family Management Style framework: Definition of the Situation, Management Behaviors, and Perceived Consequences to elicit responses related to how families access, convey, and use information [13, 14]. Mothers' demographic data included age, gender, ethnicity, educational level, socioeconomic level, relationship to child, genetic condition and status of each child, type of insurance coverage and religious affiliation.

Atlas.ti software provided support for the processing of qualitative data [15]. All interview transcripts were read through several times to gain a sense of commonly occurring themes. Using constant comparative analysis, coding categories and themes were developed following the guidelines outlined by Patton [16]. Categorizing of data that rose out of codes of all interview transcripts was conducted using the strategies recommended by Miles and Huberman [17].Following Miles and Huberman, matrix displays were constructed to display thematically categorized data across mothers of children with SCD and CF. The use of matrices enabled the author to recognize patterns as they emerged from the data. The interview data about the mothers' perceptions about the family illness experience, how they viewed their child and their experiences with their child's school were extracted and brought together into one text, which constituted the unit of analysis. Each text was then divided into meaning units that were condensed, abstracted and labeled as new categories for the purposes of the current study.

Categorizing of data and identification of categories and themes developed in this study were descriptive in nature and grounded from the conceptual framework, interview questions, and interview data. In keeping within the guidelines for qualitative research, analysis of data continued until no new information was being generated. Quotes of actual mothers' experiences that illuminate the findings were indicated.

\section{Results}

This study provided a description of the themes based on mothers' perceptions when talking about school life with mothers of children with either SCD or CF. Identifying the themes that characterized the mothers' perceptions of the school experience was made possible only after describing the experiences that mothers of children with chronic conditions encountered with their children's school systems.

Analysis of the three codes (View of Child, School and Family Illness Management) from the original study provided the basis for development for the themes for the current study. The patterns of View of Child data were placed into four categories and then labeled according to how mothers described their children in each category. The identified categories are as follows: How mothers viewed their children (healthy or unhealthy); view of child as normal or different (normal or different); child's ability to participate in self-care activities (independent/dependent) and outlook on child's future (optimistic, realistic and pessimistic). Family Illness Management (FIM) data were placed into three categories. The categories are as follows: specific behaviors and strategies in which families participate in an effort to manage child's condition, spirituality and description of responsibilities/ division of labor. School data were categorized as the following: Communication between mothers and the school system (open/selective); resources provided to the child in the school system (resources/no resources), specific mothers concerns regarding child and school (concerns/ no concerns) and confidence in school personnel (confidence/no confidence).

\section{View of child}

Mothers considered four parameters when describing how they viewed their children. These parameters included the child's current physical health, the child's adjustment to the chronic condition, the child's participation in self care activities, and the mother's outlook on the child's future. How 
the child is "viewed" by the mother is commonly linked by mothers to how many hospitalizations the child has had and how healthy they currently are. Interestingly, many mothers often described their child as "normal" or "different" without being prompted. Another interesting finding of this study was that mothers want their children to feel normal even if they treat them differently (ie, give medications/treatments, restrict activities, etc.). One mother of a child who viewed her child as normal stated: “Our life doesn't focus around $\mathrm{CF}$ or the activities [related to managing $\mathrm{CF}$ ]. We just get the other junk done so we can do what we wanna do [normal activities]."

\section{Family illness management}

Mothers relayed a wide range of family illness management strategies used to carry out and manage their children's chronic condition. The family illness management strategies included the use of specific management behaviors, spirituality and a description of responsibilities/division of labor within the family. The findings of the family illness management themes indicated mothers described a variety of strategies and behaviors used by the family to manage the child's condition in the context of the home. Two mothers indicated utilizing family illness management strategies that impacted the child in the school setting. One of those mothers stating moving the location of their residence and the other mother stated changing her job. The mother of a child with CF who moved residential locations stated: "We've moved because of a school district not handling, like his tube feedings and stuff. That kind of thing. So, we decided to move to a school district that would. Some schools have nurses, and therapists, occupational therapists and whatever but when he went into kindergarten the school had nothing. And he needs to have a nurse at school when he's there, and they didn't have one. And we said, well you need to get one, cause of IDP. And they said, well we're working on it but it never happened."

The mother of a child with CF who changed jobs reported: "I started working at the school when Alice started first grade so that I could give her pills every day... so I could watch Alice. I knew she had to take her pills." Both of these mothers chose the strategies mentioned above in order to ensure the child's daily health care needs were being met in the school setting.

\section{School}

There were four subthemes that emerged from the mothers' responses regarding the school situation: "Communication between mothers and the school system", "Resources provided to child attending school", "Specific parental concerns regarding their child and school" and "Confidence in school personnel". "Communication between mothers and the school system" indicates any form communication men- tioned by mothers when working with their child's school system. Mothers demonstrated two patterns for communication: Open and Selective. Further, mothers reported communication to be an important theme in the family-school relationship. One mother of a child with SCD illustrated her open communication with her child's school staff: "The teachers, the whole staff know about, the school staff, they all know about her illness. The principal, her teacher, and the nurse, and the secretaries in the office, they all know so when she gets sick, they'll call me and let me know. Or when she's out of school, I'll call them and let them know."

Mothers reported selective communication was used when their children were currently healthy and did not exhibit and obvious signs or symptoms of their condition. One mother stated, "We don't just go around telling everybody that they have CF. Right now, it's not a concern... When he gets older and gets into sports than I think they need to know."

"Resources provided to the child attending school" included resources such as the school nurse, individualized educational plans, 504 plans, special education classes, occupational or physical therapy while at school, tutoring provided by the school system, and other resources mentioned by the mother in the context of the school setting. "Specific parental concerns regarding their children and school" includes specific concerns that mothers stated they had regarding their children and their children's school system. These concerns included: absences, academics, peer and safety issues, communication, children using the condition as an excuse or to manipulate others and mother's concerns growing as their children grown older. Lastly, "Confidence in school personnel" is defined by the mothers as indications of the ability of the school staff to manage the health care needs of their children while at school including notifying parents of important issues with their children's status.

Overall, mothers used open communication with their children's school personnel. Mothers mentioned a variety of resources that were or were not available to their children while the child attended school and their decision in choosing whether or not to utilize these resources. Mothers stated concerns regarding the various ways in which absences due to the children's condition impacted their children. Other mother concerns included academics, peer and safety issues, communication, children using their condition as an excuse or to manipulate others and mothers' concerns growing as their children grow older. Mothers did not want their children to be treated any differently due to constraints of condition than the ways in which their children's classmates were treated.

In summary, upon examining the three themes on mothers' interview data (view of child, family illness management and school) the findings are as follows. The findings from the view of child analysis indicated that mothers considered the following four parameters when describing how they viewed 
their children: the child's current physical health, the child's adjustment to the chronic condition, the child's participation in self care activities, and the mothers' outlook on the child's future. The findings of the family illness management themes indicated mothers described a variety of strategies and behaviors used by the family to manage the child's condition in the context of the home. The findings of the school analysis indicated that "Communication between mothers and the school system", "Resources provided to the child attending school", "Specific parental concerns regarding their children and school" and "Confidence in school personnel" were factors that were important to mothers upon examining the child's school life.

\section{Discussion}

This study was directed toward advancing a better understanding of school life from the perspective of the mother of a child with a chronic condition. A primary contribution of this study is the consideration of the themes found to be important to mothers when interfacing with the school system of their children who have a chronic condition. In order to help families who have a children with chronic conditions meet their goals it is important to recognize and focus on the family as the unit of study.

The concept of normalization has been examined over the years and can be found in studies of families with children who have chronic conditions $[18,19]$. In the current study, normalization is evident with respect to how and why mothers worked within the family and between the family and school system in an attempt to manage their children's condition. Examples of working within the family include encouraging children to become responsible for their selfcare activities in an effort to reduce health care deficits. An example of attempting to achieve normalization by working with the system is how mothers educated their children's school personnel and classmates on the condition in an effort to reduce negative sequelae (i.e., management of condition while children are in school and classmates are teasing child) that might stem from the children with chronic conditions such as SCD and CF. Children who had more restrictions tended to be considered different by their mothers. This study found no differences between how mothers of SCD viewed their children vs. how mothers of children with $\mathrm{CF}$ viewed their children.

The family illness management data was explored because it is thought that understanding the sociocultural context within which these families manage the multiple aspects of their child's condition will shed some light on the familyschool life. The family illness management results from this study specifically related to the management of the condition in the home and not in the school setting. The findings in this study also demonstrate that family illness management was dependent on age, support network and severity of the child's condition.

While this study contributes to the insight of familyschool relationships in families who have children with chronic conditions, as with all research studies, there are limitations that need to be addressed. Given the nature of the sample and sampling technique used, the study's findings cannot be generalized to all families who have a child with a chronic condition without further study. Furthermore, like the results of any secondary analysis, the conclusions drawn were constrained by the purpose of the original study. There was lack of data in mother's responses that directly related to the context of the school setting because the current study was a secondary analysis of the original data. The original study's purpose was to explore the families' management of the children's illness in the context of the home. Therefore, the focus of the management was not in the context of the school setting. In addition, in the current study all of the mother's responses found in the View of Child and Family Illness Management themes that specifically related to the school setting were unplanned or spontaneous responses. Despite this limitation, the data provided by the diverse sample of mothers were of sufficient quality to permit useful interpretation concerning the nature of the families working relationship with the school system. If we had a larger sample and we were asking my questions I may have been able to develop family-school working relationship patterns. Despite the limitations, the use of secondary data allowed a single researcher to conduct this study in a manner that was time-efficient and cost-effective.

A better understanding of the dynamics between schools and families who have children with a chronic condition, such as SCD or CF, allows for development of appropriate school-based programs. However, there are children who are diagnosed with a variety of other chronic conditions that are similar to SCD and CF in terms of their invisible nature. Among those illnesses are phenylketonuria (PKU), asthma, type 1 diabetes and hemophilia disorders. Future studies need to study these aggregates as well. In conclusion, nursing research of families has the potential to positively affect families in both school-based and health care policies and practice [20]. By identifying the variables that correlate with different levels of family functioning in families with children who have chronic conditions in the school system we will be better equipped to develop interventions specific to the needs of families.

This study raised awareness of the need for educational preparation of school personnel related to caring for children with chronic conditions while in the school setting. Such educational preparation may be in the form of assistive programs that facilitate a working relationship between the family and school system. In this study, educating the school system on the needs of the child with the chronic condition was usually completed by bringing in educational materials or holding 
meetings with the school administrators and/or teachers. A school program plan needs to be developed and implemented that provides both the school and the family with the necessary information and support needed to manage the child's health care situation during the time spent at school.

Many of the mothers indicated that having older children made management easier due to the child taking on more responsibility of his or her care. The mothers who indicated having past experiences with the same school system year after year indicated management was easier because they knew the teachers and this required less exchange of information regarding the child's condition.

Future directions in advancing research in the area of family-school relationships include research on how families simultaneously manage their children's chronic conditions in the home and in the school setting. Also important is the conduction of similar studies with families who have children with a variety of chronic conditions. Conducting similar studies with a variety of chronic conditions would examine whether the description of the family-school life translates to other chronic conditions that effect children. For example, using larger sample sizes of families of children with chronic conditions such as Marfan's syndrome, hemophilia and phenylketonuria would contribute to further testing the description of the family-school working relationship constructed in this study.

\section{Acknowledgement}

Assistance with the study: None except the authors.

\section{Financial Support and Sponsorship}

None.

\section{Conflict of Interest}

None.

\section{References}

1. Kieckhefer GM, Trahms CM, Churchill SS, Simpson JN. Measuring parent-child shared management of chronic illness. Pediatr Nurs. 2009;35(2):101-108, 127.

2. Kolbe L, Kann L, Patterson B, Wechsler H, Osorio J, Collins J. Enabling the nation's schools to help prevent heart disease, stroke, cancer, COPD, diabetes, and other serious health problems. Public Health Rep. 2004;119(3):286-302.

3. Schmidt S, Petersen C, Bullinger M. Coping with chron- ic disease from the perspective of children and adolescents--a conceptual framework and its implications for participation. Child Care Health Dev. 2003;29(1):63-75.

4. Sexson SB, Madan-Swain A. School reentry for the child with chronic illness. J Learn Disabil. 1993;26(2):115$125,137$.

5. Chao P, Bryan T, Burstein K, Ergul C. Family-centered intervention for young children at-risk for language and behavior problems. Early Childhood Education Journal. 2006;34:147-153.

6. Concepcion M, Murphy S, Canham D. School nurses' perceptions of family-centered services: commitment and challenges. J Sch Nurs. 2007;23(6):315-321.

7. Dearing E, Kreider H, Simpkins S, Weiss H. Family involvement in school and low-income children's literacy: Longitudinal associations between and within families. Journal of Educational Psychology. 2006;98:653-664.

8. Adams K, Christenson S. Trust and the family-school relationship examination of parent-teacher differences in elementary and secondary grades. Journal of School Psychology. 2000;38(5):477-497.

9. Blue-Banning M, Summers J.A, Frankland HC, Nelson LL Beegle G. Dimensions of family and professional partnerships: Constructive guidelines for collaboration. Exceptional Children. 2004;70(2):167-184.

10. Bryk AS, Schneider B. Trust in schools: A core resource for improvement. New York, NY: Russell Sage Foundation; 2002.

11. Denboba D, McPherson MG, Kenney MK, Strickland B, Newacheck PW. Achieving family and provider partnerships for children with special health care needs. Pediatrics. 2006;118(4):1607-1615.

12. Gallo A, Knafl K, Angst D. Parent's interpretation and use of genetic information. Funded by the National Institutes of Health, National Human Genome Research Institute, Ethical, Legal \& Social Implications Program; 2001.

13. Knafl KA, Deatrick JA. Further refinement of the family management style framework. J Fam Nurs. 2003;9(3):232-256.

14. Knafl K, Breitmayer B, Gallo A, Zoeller L. Family response to childhood chronic illness: description of management styles. J Pediatr Nurs. 1996;11(5):315-326.

15. Atlas.ti: The knowledge workbench [computer program]. Thousand Oaks, CA: Scolari Sage Publication Software; 1997.

16. Patton MQ. Qualitative Research \& Evaluation Methods. 3rd ed. Thousand Oaks, CA: Sage Publications; 2002.

17. Miles M. Huberman A. Qualitative data analysis: An expanded sourcebook. Thousand Oaks, CA: Sage Publications; 1994.

18. Deatrick JA, Knafl KA, Murphy-Moore C. Clarify- 
ing the concept of normalization. Image $\mathrm{J}$ Nurs Sch. 1999;31(3):209-214.

19. Knafl KA, Darney BG, Gallo AM, Angst DB. Parental perceptions of the outcome and meaning of normalization. Res Nurs Health. 2010;33(2):87-98.
20. Meister S. Health care financing, policy, and family nursing practice: New opportunities. In: Gilliss C, Highley B, Roberts B, Martinson J, eds. Toward a science of family nursing. New York, NY: Addison-Wesley; 1989:146-155. 